\title{
CARACTERIZAÇÃO E APLICAÇÃO DE CASCA E CINZA DA CASCA DE ARROZ PARA EMPREGO EM ARGAMASSA DE CIMENTO PORTALND
}

\section{ARTIGO ORIGINAL}

RIPOLI FILHO, Francisco ${ }^{1}$, BAESSO, Matheus Henrique 2, RIZZATTI, Eduardo ${ }^{3}$, SOARES, José Mário Doleys ${ }^{4}$

RIPOLI FILHO, Francisco. Et al. Caracterização e aplicação de casca e cinza da casca de arroz para emprego em argamassa de cimento portalnd. Revista Científica Multidisciplinar Núcleo do Conhecimento. Ano 06, Ed. 06, Vol. 03, pp. 174193. Junho de 2021. ISSN: 2448-0959, Link de acesso: https://www.nucleodoconhecimento.com.br/engenharia-civil/cimento-portalnd, DOI: 10.32749/nucleodoconhecimento.com.br/engenharia-civil/cimento-portalnd

\section{RESUMO}

O desenvolvimento sustentável está intimamente ligado a dois aspectos: limitação de uso de recursos naturais e desenvolvimento econômico. Nesse sentido, a disposição inadequada de resíduos da agroindústria resulta em danos ao meio ambiente. Por outro lado, a construção civil apresenta uma boa oportunidade para reutilização

${ }^{1}$ Doutor em Engenharia Civil, Mestre em Engenharia de Produção, Especialização em Engenharia de Segurança e Graduado em Engenharia Civil.

${ }^{2}$ Bacharelando em Engenharia de Energia.

${ }^{3}$ Orientador. Doutorado em Engenharia Civil.

${ }^{4}$ Orientador. Doutorado em Engenharia Civil.

RC: 87828

Disponível em: https://www.nucleodoconhecimento.com.br/engenharia-civil/cimento-portalnd 
desses materiais. Assim, com o objetivo de compatibilizar com princípios de sustentabilidade, esta pesquisa investigou materiais considerados resíduos industriais da cultura do arroz. Desse modo, foram caracterizadas tanto a casca de arroz e a cinza proveniente de sua queima quanto a química e física de suas propriedades. Além disso, foram realizados testes de difração por raios $\mathrm{X}$. O primeiro material foi objetivado como substituinte parcial de agregado miúdo e o segundo como substituinte parcial de cimento para uso em argamassas de cimento Portland. Por fim, foram avaliados quatro traços de argamassa (1:3 e 1:4, com e sem adição de cinza) quanto à relação água/aglomerante e resistência à compressão simples. Logo, foi comprovada a possibilidade de execução de argamassas com os materiais avaliados, desde que realizados adequados processos de dosagem.

Palavras chaves: casca de arroz, cinza de casca de arroz, argamassa de cimento Portland.

\section{INTRODUÇÃO}

É fato que um dos setores que mais produzem resíduos é o da agroindústria. Anualmente, é produzida uma enorme quantidade de produtos de consumo alimentício, com destaque para os cereais, os quais geram resíduos, como cascas e farelos. Partindo deste pressuposto, cabe salientar que a utilização de matériasprimas disponíveis de forma abundante em regiões específicas tem o potencial de trazer transformação econômica, tendo em vista que esses resíduos podem ser subaproveitados. Além disso, há a possibilidade de redução de custos, pois a reciclagem de resíduos propicia uma diversificação da oferta de matéria-prima utilizada como material de construção, o que contribui para a preservação ambiental (LIMA, 2005; JOHN, 2000).

Nesse sentido, a produção de arroz no Brasil visa, principalmente, o abastecimento do mercado interno. Assim, a produção deste produto no país, em 2020, é estimada em 10,9 milhões de toneladas, girando em torno da produção do estado do Rio Grande 
do Sul, responsável por $80 \%$ da oferta nacional (COHAB, 2020). Cabe destacar que o processo de beneficiamento de arroz gera como principal resíduo sua casca. Contudo, devido ao seu baixo valor nutritivo, caráter abrasivo e alta resistência à degradação, as cascas não apresentam nenhuma aplicação direta.

Dessa forma, os principais constituintes da casca de arroz (CA) são a celulose (30\% em massa), a lignina (22\% em massa) e resíduos inorgânicos (40\% em massa). Em função da espécie, clima e região geográfica do plantio do arroz, o resíduo pode conter até $89 \%$ de sílica em massa (CARVALHO, 2004). É um resíduo classificado como Classe II A, ou seja, não inerte e não perigoso, tanto em relação à saúde humana quanto ao impacto ao meio ambiente, o qual apresenta propriedades como biodegradabilidade, combustibilidade e solubilidade em água (ABNT, 2004). Por outro lado, quando incinerada em ambientes fechados, resulta em liberação de $\mathrm{CO}$ e $\mathrm{CO}_{2}$. Ademais, seu descarte é muito comum em lavouras e fundos de rios, onde sua decomposição libera gás metano, considerado cerca de $50 \%$ mais nocivo que o $\mathrm{CO}_{2}$ para o meio ambiente.

Ainda assim, uma considerável quantidade desse resíduo é reutilizada dentro da própria usina de beneficiamento, na geração de calor para realização do processo de parbolização dos grãos. Quando queimadas, seja a céu aberto ou em fornos especiais à temperatura controlada, as cascas resultam em cinzas que têm um bom potencial energético, devido sua composição química em que há predominância da sílica (CARVALHO, 2004; MILANI, 2008).

Outrossim, a temperatura e tipo de queima é um fator determinante para definir a morfologia do material. (TASHIMA; SILVA; AKASAKI, 2004). O teor de sílica presente na cinza é inversamente proporcional ao percentual de perda ao fogo (POUEY, 2008). Dessa forma, a atividade pozolânica da cinza de casca de arroz (CCA) está relacionada de forma direta à composição morfológica, ao tempo de moagem e de queima.

RC: 87828

Disponível em: https://www.nucleodoconhecimento.com.br/engenharia-civil/cimento-portalnd 
Nessa perspectiva, é possível analisar estudos que verificaram que a pozolana produzida a uma temperatura de $600 \stackrel{\circ}{\mathrm{C}}$ apresenta o maior valor de superfície específica. Quando produzida na faixa de temperatura entre 600 e $900{ }^{\circ} \mathrm{C}$, apresenta uma redução no valor desta superfície, fato que foi atribuído ao aumento do tamanho das partículas.

Para o caso específico do aumento de 800 para $900 \stackrel{\circ}{\mathrm{C}}$ de temperatura, foi possível identificar, ainda, a influência do processo de nucleação que ocorre na sílica para a formação de cristais de cristobalita (HANAFI et al., 1980). A temperatura de queima ótima se situa entre 500 e $700^{\circ} \mathrm{C}$, em que não ocorre cristalização da sílica, tornandose amorfa e caracterizada por alta reatividade, formato angular, estrutura altamente celular e superfície específica elevada (MEHTA, 1992; NAIR, et al., 2008).

Nesse cenário, a construção civil é a atividade do ramo tecnológico que mais utiliza recursos naturais, o que, por conseguinte, ocasiona um considerável impacto ambiental. Por esta razão, é um ramo indicado para assimilar parte considerável dos resíduos sólidos, tanto aqueles gerados na própria atividade de construção, denominados de entulhos, quanto os resíduos gerados a partir de outras atividades industriais (ISAIA, 1995). Em função de seu baixo custo, baixa granulometria e considerável área específica, a sílica de CA se tornou assunto de diversas pesquisas no âmbito acadêmico, principalmente no desenvolvimento de materiais alternativos para construção civil. Contudo, estudos são necessários para propiciar a correta inserção desses novos materiais (BEZERRA, 2010; HARIMA; SOUZA, 1996).

A utilização da cinza e CA como agregado, no lugar da sua disposição no meio ambiente propicia benefícios econômicos, visto que, entre os materiais que fazem parte do traço de um concreto, o que gera um custo maior é o cimento. Para mais, tem-se, também, a redução do consumo de cimento em concretos e argamassas, o que implica na redução de custos no final do processo. Algumas pesquisas já evidenciaram a possibilidade de substituição parcial do agregado miúdo por CA em argamassas para aplicações em vedações, sob o ponto de vista mecânico e de 
isolamento térmico. (CARVALHO, 2004; ISAIA, 1987; MARTINEZ et al., 2005; FERREIRA et al., 2008). Ainda, outras evidenciaram a possibilidade de utilização da CCA como adição mineral ao cimento, com resultados até superiores aos convencionais (FERREIRA, 2003; TIBONI, 2007; SOUZA, 2008).

Nesse contexto, a sílica age em concretos e argamassas de duas formas diferentes. Uma delas é por processo químico, por meio da reação pozolânica, reagindo com o hidróxido de cálcio e formando silicatos de cálcio hidratados (C-S-H), o que favorece a resistência da pasta de cimento (BEZERRA, 2010). A outra forma de ação é física, por meio do efeito de filler inerte, no qual a sílica preenche os vazios, gera um efeito de empacotamento das partículas e torna o material menos vulnerável a agentes agressivos (BUI; HU; STROEVEN, 2005). Além disso, ocorre a refinação da estrutura de poros do material, o que aumenta a disponibilidade de locais para nucleação dos compostos do cimento hidratado (SOUZA, 2008). Ainda, como forma de elevar o desempenho mecânico e químico, a moagem da cinza confere uma elevada atividade pozolânica ao material (SILVA, 2009).

Portanto, é importante conhecer a morfologia superficial das fibras desses materiais, visto que rugosidade, tamanho dos poros (vasos) e comprimento das fibras são fatores que estão diretamente relacionadas com as capacidades de adesão por compatibilidade, homogeneização e afinidade entre os materiais na interface fibra/matriz polimérica. Por sua vez, essas capacidades são conclusivas para as propriedades mecânicas finas do compósito (MARINELLI et al., 2008). Ademais, o consumo de água em concretos e argamassas com adições minerais depende da forma e superfície específica de suas partículas e da quantidade utilizada como incorporação em substituição ao cimento (DAL MOLIN; VIEIRA; LIMA, 2004).

Desse modo, o presente trabalho visou avaliar e propor a utilização de casca e CCA como materiais para produção de argamassas, as quais são utilizadas na produção de blocos de vedação para habitações. Tal avaliação é realizada em relação a caracterização dos materiais, observando propriedades físicas, químicas e 
termográficas. Por fim, uma argamassa teste com CA como agregado foi avaliada com e sem a inserção de cinzas, sua relação água/aglomerante e equacionou-se uma dosagem com cimento.

\section{MATERIAIS E MÉTODOS}

A utilização de resíduos que seriam descartados no meio ambiente propicia vários benefícios. Entre eles, citam-se a eliminação de custos para o descarte, redução dos locais de disposição, redução do consumo de agregados naturais, preservação do solo, instalação de atividades produtivas e geração de empregos, entre outros.

Assim, neste estudo a utilização da casca de arroz e da cinza de casca de arroz na argamassa está definida pelos propósitos a seguir descritos.

\subsection{CASCA DE ARROZ}

A CA tem como função, neste estudo, substituir parcialmente o agregado miúdo. Proveniente de um comercial de arroz, essa passou por um processo de peneiramento para retirada dos resíduos maiores que $6,3 \mathrm{~mm}$. Assim, foram realizadas as caracterizações físicas: finura na peneira ABNT n 200 (ABNT, 2014) e massa unitária no estado solto (ABNT, 2006). Além disso, análise química (ABNT, 2012) foi realizada para determinação dos principais óxidos presentes e perda ao fogo. Ainda, a difração de raios $\mathrm{X}$ e o microscópio eletrônico de varredura (MEV) foram utilizados para avaliação microscópica da estrutura do material.

Diante desses fatores, foi realizado um processo de tratamento de choque térmico, em que a casca passou por duas horas com temperatura entre 80 e $90^{\circ} \mathrm{C}$ imersa em água e, posteriormente, foi deixada secar a peso constante, conforme a Figura 1. Essa ação foi utilizada no intuito de "abrir" a casca, tornando-a mais compatível com os outros materiais da argamassa. Após isso, foi avaliado o teor de absorção de água antes e após o processo.

RC: 87828

Disponível em: https://www.nucleodoconhecimento.com.br/engenharia-civil/cimento-portalnd 
Figura 1 - Etapas do preparo da CA

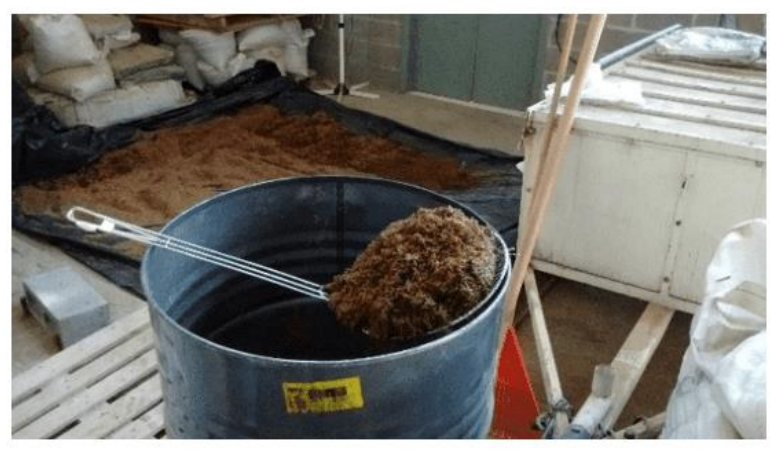

(a) fervura a $85^{\circ} \mathrm{C}$

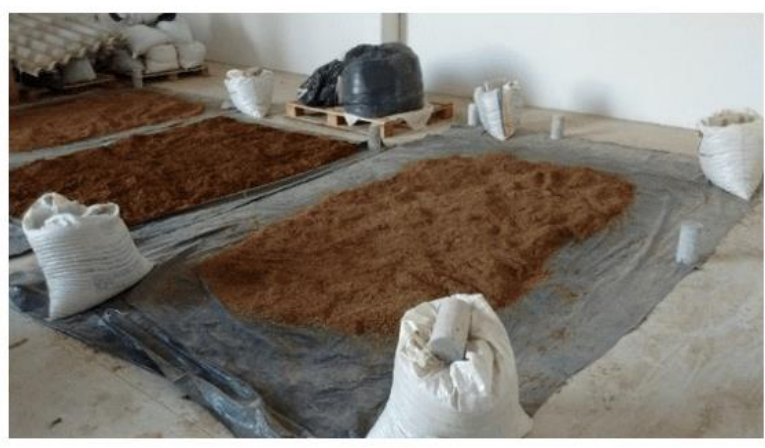

(b) estado de secagem

Fonte: Autor (2017)

\subsection{CINZA DA CASCA DE ARROZ}

A cinza utilizada neste estudo é proveniente da queima da $\mathrm{CA}$ em forno cerâmico tipo Hoffmann, temperatura aproximada de $800^{\circ} \mathrm{C}$, as etapas do preparo da CCA podem ser vizualizadas na Figura 2. A utilização dessa decorreu-se por maiores acréscimos de cinzas na argamassa, como substituinte parcial do cimento, bem como evitar a colocação em meios impróprios e poluentes. Após 20 minutos de moagem em moinho de bola, foi realizada a caracterização física por: finura na peneira ABNT $n^{\circ} 200$, massa unitária no estado solto, superfície específica (Blaine) (ABNT, 2015) e massa específica (ABNT, 2017). Além desses, uma análise granulométrica por difração à laser foi executada, utilizando o método de dispersão de partículas em fase líquida associado a um processo de medida óptica no equipamento CILAS - modelo 1064. Para realização deste ensaio, as amostras foram passadas na peneira ABNT n 200 , dispersas em álcool anidro e empregadas no ultrassom por 60 segundos. Cabe destacar que um fotodiodo a laser emite um feixe de luz que é captado por um sistema óptico que ativa o líquido com o pó a ser analisado. Ademais, foram realizadas verificações por difração de raios $X$.

RC: 87828

Disponível em: https://www.nucleodoconhecimento.com.br/engenharia-civil/cimento-portalnd 
Figura 2 - Etapas do preparo da CCA

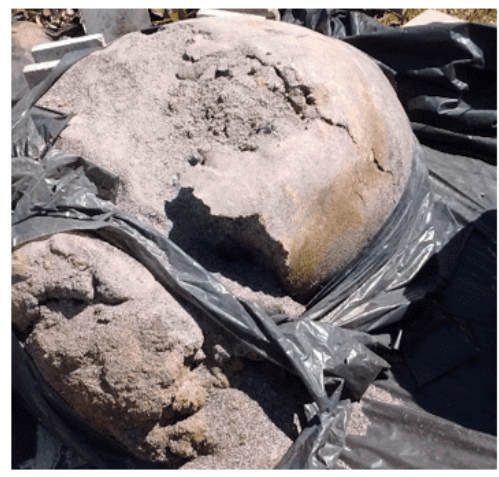

(a) cinza recolhida do forno

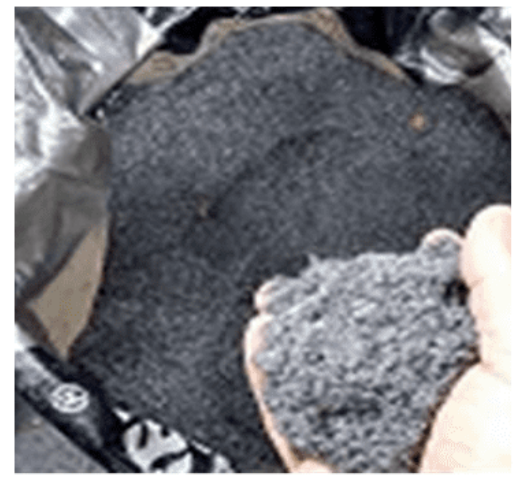

(b) cinza "in natura"

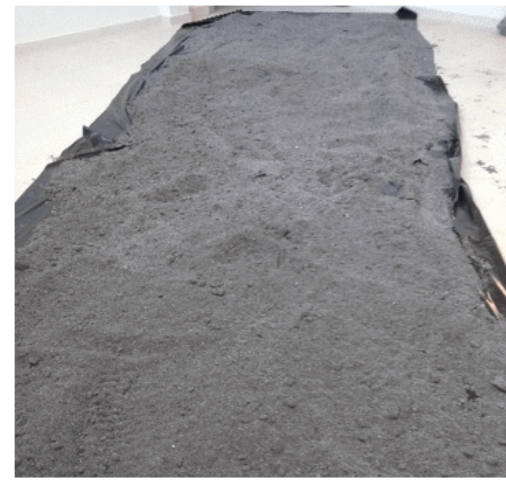

(c) estado de secagem

Fonte: Autor (2017)

Nesta situação, quando adicionada em argamassas, a cinza e a cal hidratada possuem propriedades que favorecem a mistura, como, por exemplo, a trabalhabilidade, aderência e rendimento. Assim, como o objetivo do estudo é caracterizar os materiais para emprego em argamassa, foi verificada a atividade pozolânica da cinza com cal (ABNT, 2015). As características da cal utilizada serão abordadas no item seguinte.

\subsection{ARGAMASSA TESTE}

Para correlacionar com o objetivo deste o estudo, uma argamassa foi composta com os materiais: cimento CP II-Z com e sem adição de cinza, areia e CA como aglomerantes e cal. Com base na pesquisa de Souza (2008), foram utilizados teores de $12 \%$ de casca e $15 \%$ de cal em massa. Como caracterização destes materiais, foi efetuada uma análise química dos principais óxidos constituintes da areia, cal e cimento utilizados.

Assim, os traços de 1:3 e 1:4 foram escolhidos para avaliar a relação água/aglomerante padrão da argamassa (Figura 3), com e sem adição de 10\% de

$\mathrm{RC}: 87828$

Disponível em: https://www.nucleodoconhecimento.com.br/engenharia-civil/cimento-portalnd 
CCA (Tabela 1). Utilizando três traços de relação água/aglomerante $(0,46 ; 0,57 \mathrm{e}$ $0,69)$, quatro corpos de prova cilíndricos $(50 \times 100 \mathrm{~mm})$ foram moldados e ensaiados a compressão simples aos 28 dias para cada traço. Uma análise de variância ANOVA, seguida de teste Tukey, foi utilizada na determinação de intervalos de confiança significativos para as combinações de fatores água/aglomerante. Por fim, uma análise no microscópio eletrônico de varredura foi utilizada para análise da estrutura do composto para verificação das superfícies de ruptura.

Tabela 1 - Traços utilizados na composição das argamassas, em volume

\begin{tabular}{|l|l|l|l|}
\hline Nomenclatura & Traço de cimento & CCA $(\%)$ & (Cim:CCA):Areia:CA:Cal \\
\hline Puro 1:3 & $1: 3$ & 0 & $(1,00: 0,00): 1,92: 0,48: 0,60$ \\
\hline CCA 1:3 & $1: 3$ & 10 & $(0,90: 0,10): 1,92: 0,48: 0,60$ \\
\hline Puro 1:4 & $1: 4$ & 0 & $(1,00: 0,00): 2,56: 0,64: 0,80$ \\
\hline CCA 1:4 & $1: 4$ & 10 & $(0,90: 0,10): 2,56: 0,64: 0,80$ \\
\hline
\end{tabular}

Fonte: Autor (2017)

Figura 3 - Argamassa desde o preparo até o rompimento

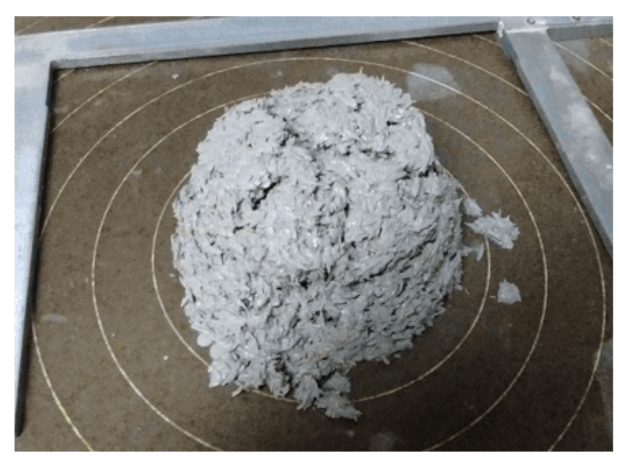

(a) determinação da consistência

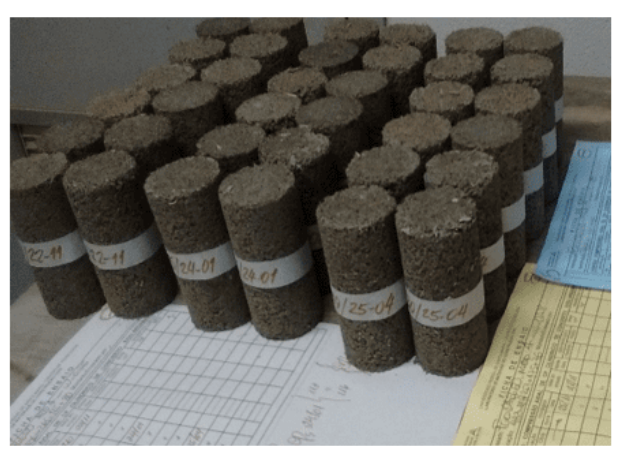

(b) moldagens e controle

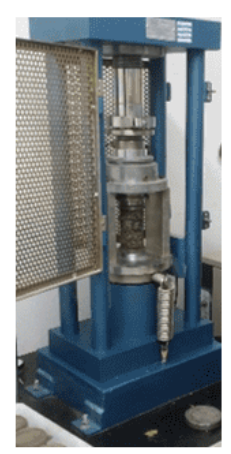

(c) rompimento

Fonte: Autor (2017)

RC: 87828

Disponível em: https://www.nucleodoconhecimento.com.br/engenharia-civil/cimento-portalnd 


\section{RESULTADOS E DISCUSSÕES}

A partir dos resultados obtidos das características de cada componente presente na argamassa, dos ensaios de resistência destas, dos estudos e análises dos traços, do desenvolvimento de formas a aplicação em subprodutos bem como da avaliação estatística dos resultados, tem-se as seguintes conclusões:

\subsection{CARACTERIZAÇÃO DA CASCA DE ARROZ}

Com base nos resultados de caracterização física da CA, essa apresenta massa unitária de $0,117 \mathrm{~g} / \mathrm{cm}^{3}$, um material leve e volumoso, provavelmente relacionado ao tipo de estrutura física côncava e oca dessa. Sua dimensão máxima resultante foi de 4,8 mm. Quando comparado ao módulo de finura de um agregado miúdo normalmente empregado na construção civil, seu módulo de finura de 5,80 é aproximadamente o dobro da areia.

Nessa perspectiva, a análise química da CA (Tabela 2) apresenta $\mathrm{SiO}_{2}$ como constituinte majoritário. Essa quantidade de sílica é favorável para que ela seja considerada um material pozolânico, ou seja, quando finamente moído e em presença de umidade, reage quimicamente com o hidróxido de cálcio formando compostos mais densos e menos solúveis. Além do mais, o baixo percentual de perda ao fogo (P.F.) sugere que a casca tenha sido queimada em altas temperaturas (possivelmente $800^{\circ} \mathrm{C}$ ou por longos tempos).

Tabela 2. Análise química da CA e perda ao fogo

\begin{tabular}{l|l|l|l|l|l|l|l|l|l|}
$\begin{array}{l}\text { Óxidos } \\
\text { constituintes }\end{array}$ & $\mathrm{SiO}_{2}$ & $\mathrm{Al}_{2} \mathrm{O}_{3}$ & $\mathrm{Fe}_{2} \mathrm{O}_{3}$ & $\mathrm{CaO}$ & $\mathrm{MgO}$ & $\mathrm{SO}_{3}$ & $\mathrm{Na}_{2} \mathrm{O}$ & $\mathrm{K}_{2} \mathrm{O}$ & P.F. \\
\hline CA, massa (\%) & 91,87 & 0,39 & 0,41 & 1,14 & 0,56 & 0,22 & 0,08 & 1,85 & 1,21 \\
\hline
\end{tabular}

Fonte: $A B C P(2017)$

$\mathrm{RC}: 87828$

Disponível em: https://www.nucleodoconhecimento.com.br/engenharia-civil/cimento-portalnd 
Pela difração de raios $X$ da CA sem tratamento térmico (Figura 4), observa-se um desvio na linha base entre os ângulos de 15 e $30^{\circ}$, o que caracteriza um material com estrutura sem ordenamento a longo alcance, ou seja, típico de um material amorfo, validando seu uso como aglomerante de argamassa.

Figura 4 - Difração de raios X da CA

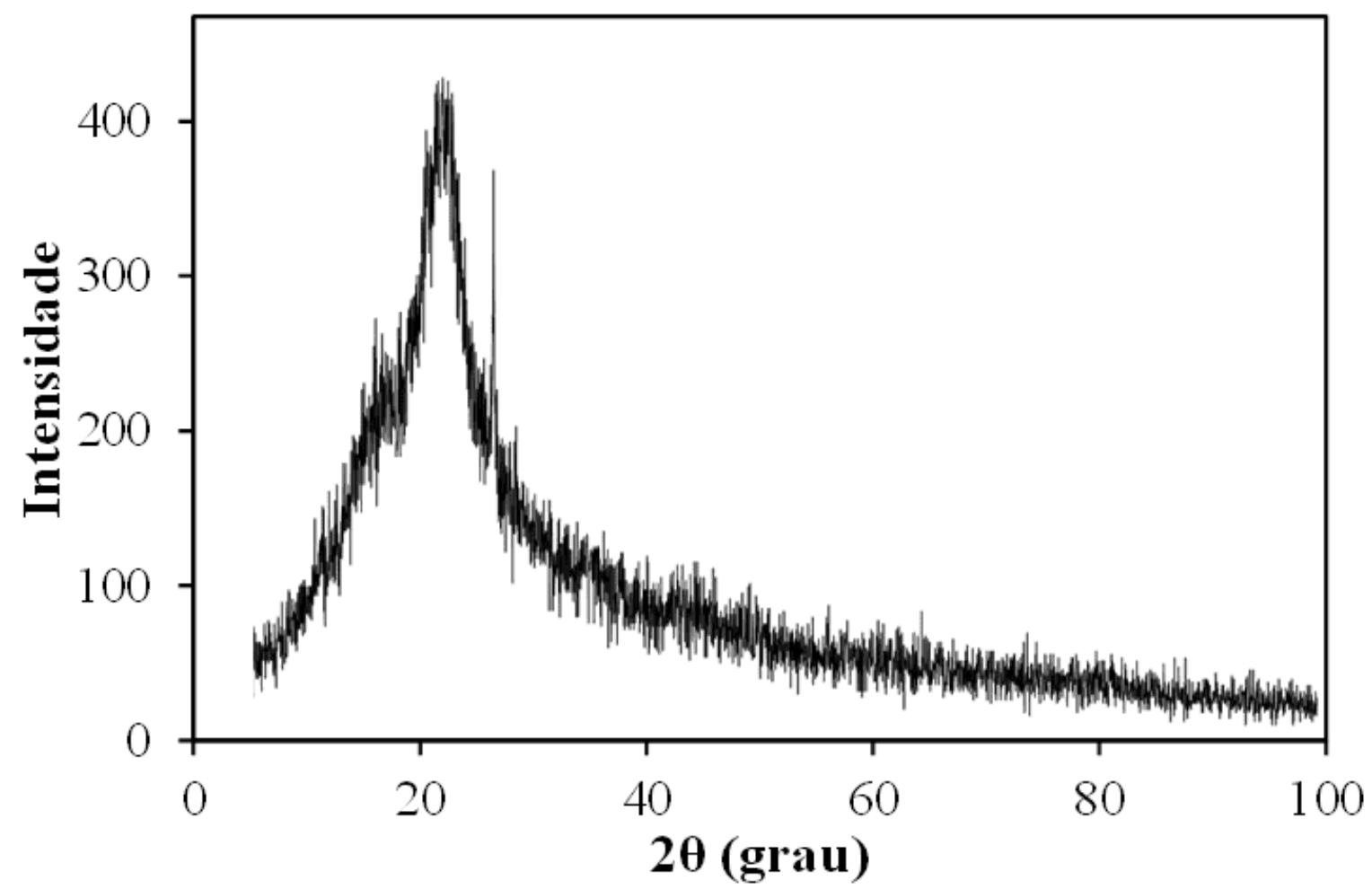

Fonte: CADEQ (2017)

Após realizado o processo de tratamento térmico em água quente à $85^{\circ} \mathrm{C}$ (média), por duas horas, visando melhor compatibilidade da CA com os demais materiais constituintes da argamassa, foi realizado um processo de verificação da estrutura microscópica pelo MEV (Figura 5).

$\mathrm{RC}: 87828$

Disponível em: https://www.nucleodoconhecimento.com.br/engenharia-civil/cimento-portalnd 
Figura 5 - Microscópio eletrônico de varredura da CA: superfície externa (A e B) e interna $(C)$ da casca in natura; superfície externa (D e E) e superfície interna $(F)$ da casca após banho em $85^{\circ} \mathrm{C}$
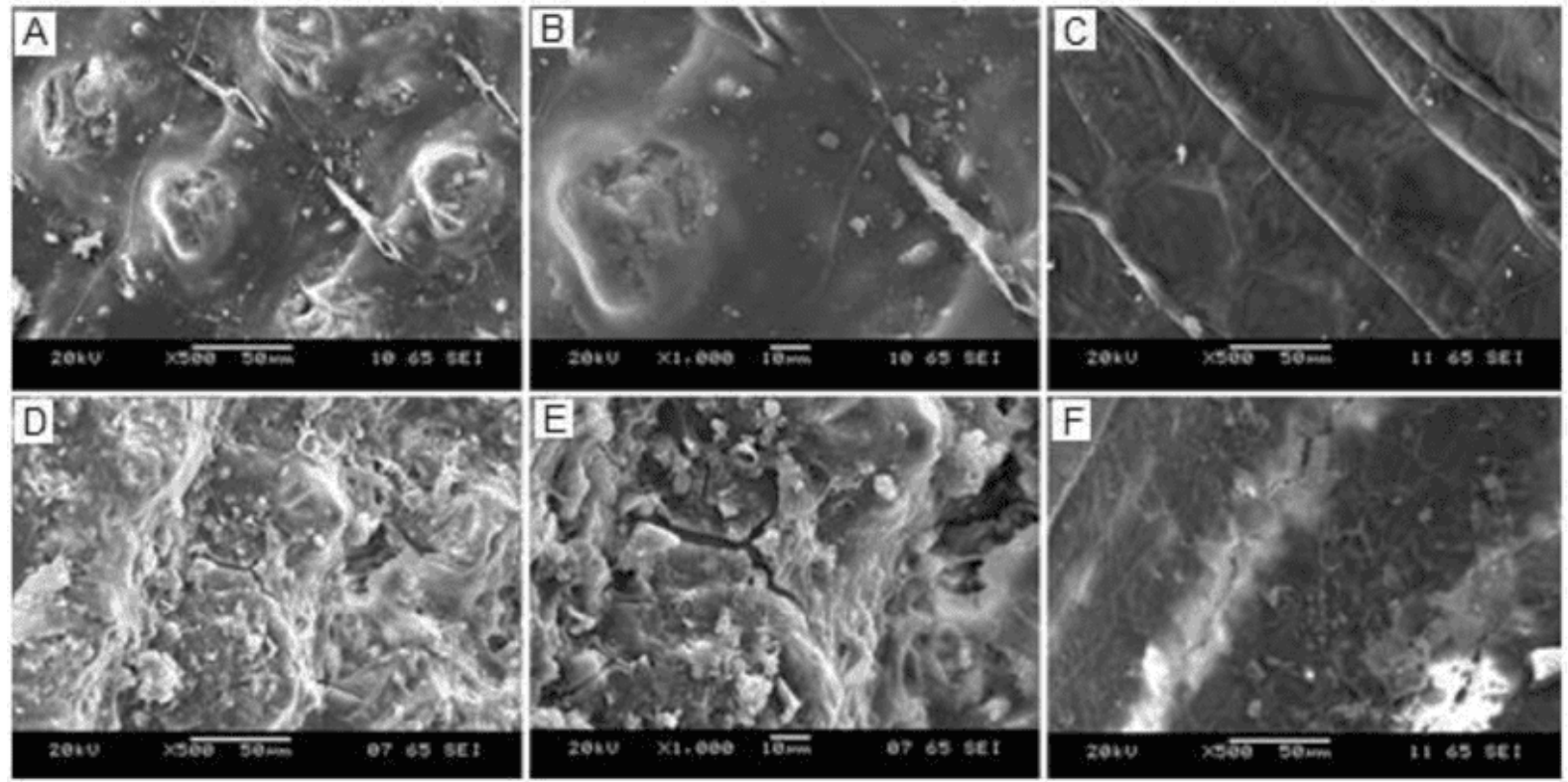

Fonte: Laboratório de Metalurgia Física - DEM/UFSM (2017)

As micrografias da $\mathrm{CA}$ in natura (Figura 5: A, B e C) mostram uma estrutura de superfície lisa, recoberta por camadas de ceras e extrativos. Após o "banho", as micrografias (Figura 5: D, E e F) indicam que parte das impurezas foi removida pelo processo, o que contribuiu para a afinidade entre as superfícies dos materiais na composição da argamassa. Isso ocorre devido a remoção de parte da cera, que é repelente, e pela diminuição da tensão superficial entre a superfície da casca e a água.

Para mais, comparando-se as superfícies internas e externas antes a após o processo de tratamento, além da remoção dos extrativos e da cera, é verificado um aumento significativo na aspereza da superfície e o surgimento de estruturas craqueladas, fatores que favorecem a adesão e a incorporação da CA pela argamassa.

Dessa forma, conhecer o teor de absorção de água é importante para realizar, posteriormente, correções no fator água/aglomerante da argamassa. A Tabela 3

RC: 87828

Disponível em: https://www.nucleodoconhecimento.com.br/engenharia-civil/cimento-portalnd 
apresenta os resultados da CA in natura e após tratamento térmico. Assim, devido aos elevados valores de absorção encontrados para a CA fervida, verificou-se a necessidade de uma prévia molhagem do material, de modo a prevenir maiores alterações no fator água/aglomerante da mistura.

Tabela 3. Aborção média por imersão em água da CA

\begin{tabular}{|l|l|l|l|l|}
\hline \multirow{2}{*}{ Material } & \multicolumn{4}{|l}{ Absorção (\%) } \\
\cline { 2 - 5 } & $\mathbf{1 h}$ & $\mathbf{5 h}$ & $\mathbf{1 2 h}$ & $\mathbf{2 4 h}$ \\
\hline Casca de arroz natural & 85,30 & 103,96 & 107,87 & 113,50 \\
\hline Casca de arroz fervida & 146,81 & 170,33 & 179,67 & 184,26 \\
\hline
\end{tabular}

Fonte: Autor (2017)

\subsection{CARACTERIZAÇÃO DA CINZA DA CASCA DE ARROZ}

A CCA teve como resultados de caracterização física: massa específica $2,23 \mathrm{~g} / \mathrm{cm}^{2}$, área específica $0,6 \mathrm{~m}^{2} / \mathrm{g}$ e resíduo em peneira $45 \mu \mathrm{m}$ de $9,2 \%$. Pela granulometria a laser, o tamanho médio das partículas é de 13,9 $\mu \mathrm{m}$. Além disso, 90\% das partículas possuem diâmetro de até $41,8 \mu \mathrm{m}$ e apenas $10 \%$ das partículas possuem diâmetro abaixo de $2,3 \mu \mathrm{m}$.

Nesse âmbito, ao avaliar a difração de raios $X$ da CCA (Figura 6), é possível verificar que essa apresenta reflexões referentes as fases cristalinas quartzo $(Q)$, cristobalita (C) e tridimita $(T)$. Essas fases cristalinas formadas indicam que as cinzas foram queimadas em temperaturas próximas ou superiores a $800^{\circ} \mathrm{C}$, o que pode reduzir a reatividade pozolânica (ISAIA, 1995). É válido salientar que um tempo de combustão longo causa colapso da estrutura celular e também da junção dos poros, o que provoca a redução da superfície específica observada.

RC: 87828

Disponível em: https://www.nucleodoconhecimento.com.br/engenharia-civil/cimento-portalnd 
Figura 6. Difração de raios $X$ da CCA

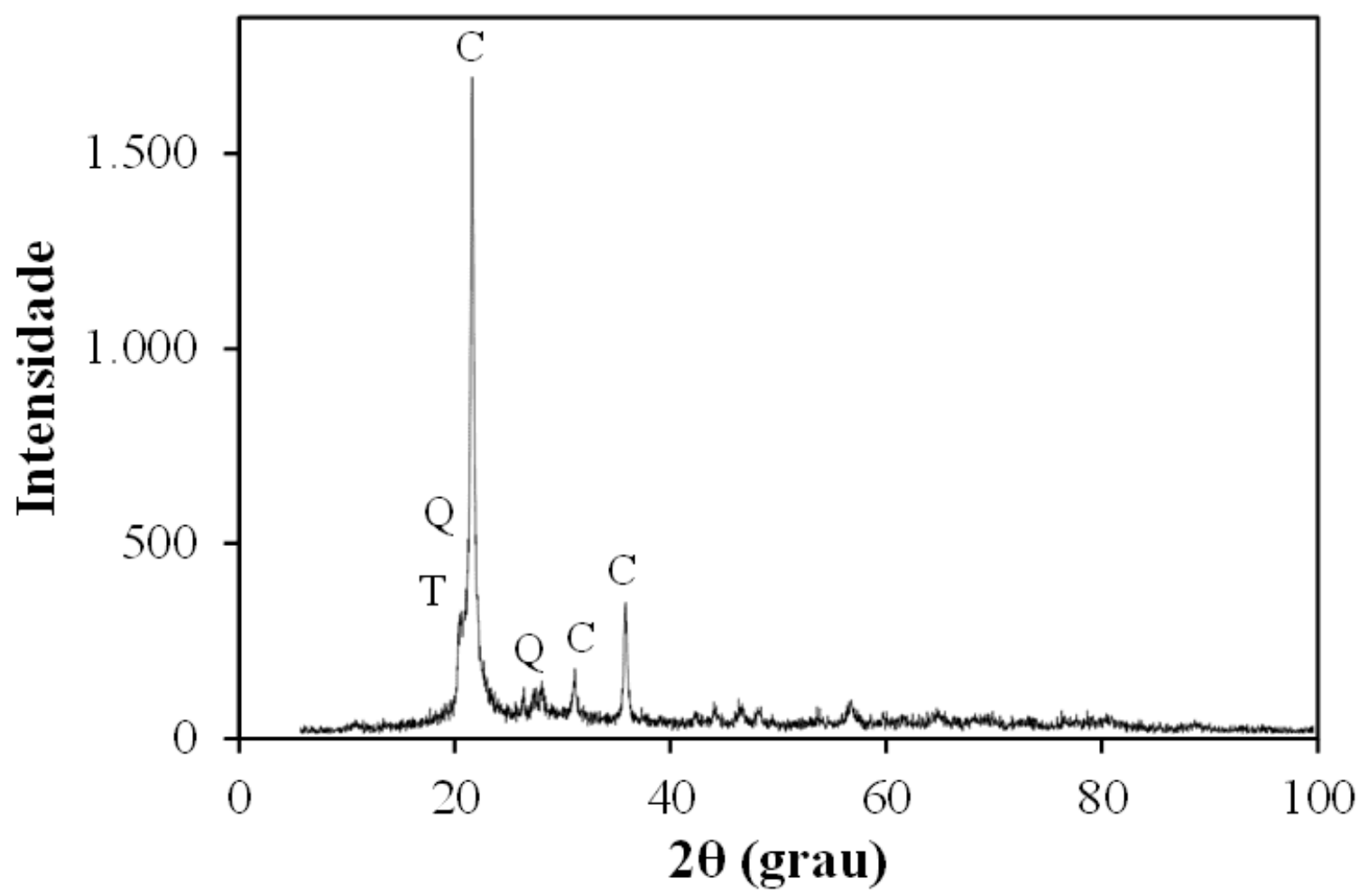

Fonte: $C A D E Q(2017)$

$\mathrm{Na}$ determinação da atividade pozolânica com cal, amostras são moldadas e ensaiadas aos sete dias por compressão e, desse modo, é determinada a média de pelo menos três amostras. Os resultados apresentaram uma resistência média de 2,5 MPa, inferior ao limite especificado pela NBR 12653 (ABNT, 2015) de 6,0 MPa. Ainda assim, a pesquisa foi continuada para verificar a viabilidade de uso em argamassas para blocos de vedação.

\subsection{COMPOSIÇÃO ARGAMASSA}

Quatro diferentes traços, divididos em três relações água/aglomerante, foram compostos para esta pesquisa. Na composição de uma argamassa para o experimento, foram adicionados aos materiais já caracterizados anteriormente, 
cimento CP II-Z, cal e areia. A Tabela 4 mostra a análise química realizada nos demais materiais.

Tabela 4. Análise química dos contituintes da argamassa: cimento, areia e cal

\begin{tabular}{|c|c|c|c|c|c|c|c|c|c|c|}
\hline $\begin{array}{l}\text { Óxidos } \\
\text { constituinte } \\
\text { s }\end{array}$ & $\mathrm{SiO}_{2}$ & $\begin{array}{l}\mathrm{Al}_{2} \mathrm{O} \\
3\end{array}$ & $\begin{array}{l}\mathrm{Fe}_{2} \mathrm{O} \\
3\end{array}$ & $\mathrm{CaO}$ & $\mathrm{MgO}$ & $\mathrm{SO}_{3}$ & $\begin{array}{l}\mathrm{Na}_{2} \\
\mathrm{O}\end{array}$ & $\mathrm{K}_{2} \mathrm{O}$ & $\begin{array}{l}\mathrm{TiO} \\
2\end{array}$ & $\begin{array}{l}\mathrm{Mn} \\
\mathrm{O}\end{array}$ \\
\hline $\begin{array}{l}\text { Cimento, } \\
\text { massa (\%) }\end{array}$ & $\begin{array}{l}20,5 \\
3\end{array}$ & 4,95 & 2,82 & $\begin{array}{l}56,7 \\
5\end{array}$ & 2,72 & $\begin{array}{l}2,0 \\
3\end{array}$ & 0,08 & $\begin{array}{l}1,4 \\
5\end{array}$ & - & - \\
\hline $\begin{array}{l}\text { Areia, } \\
\text { massa (\%) }\end{array}$ & $\begin{array}{l}84,0 \\
0\end{array}$ & 9,10 & 1,40 & 6,60 & 0,10 & & 0,90 & $\begin{array}{l}2,7 \\
0\end{array}$ & $\begin{array}{l}0,4 \\
0\end{array}$ & - \\
\hline $\begin{array}{l}\text { Cal, massa } \\
(\%)\end{array}$ & 3,30 & 0,80 & 0,60 & $\begin{array}{l}62,0 \\
0\end{array}$ & $\begin{array}{l}33,0 \\
0\end{array}$ & & - & $\begin{array}{l}0,1 \\
0\end{array}$ & - & 0,10 \\
\hline
\end{tabular}

Fonte: $A B C P / S P(2017)$

No cimento pesquisado, pode-se observar um alto índice de óxido de cálcio quando comparado aos demais óxidos (56,75\%), os quais estão de acordo com os requisitos da NBR 16697 (ABNT, 2018). Para a areia, a maior participação da sílica já era esperada, o que resultou em $84 \%$ de $\mathrm{SiO}_{2}$ em sua composição, seguida por $\mathrm{Al}_{2} \mathrm{O}_{3}$ e $\mathrm{CaO}$. Na composição da cal, observa-se, majoritariamente, a presença de $\mathrm{CaO}(62 \%)$ e $\mathrm{MgO}(33 \%)$.

A Tabela 5 apresenta o resultado de análise de variância e teste Tukey para os grupos de traços analisados. Na Figura estão apresentados os resultados da compressão simples aos 28 dias, bem como suas linhas de tendência. 
Tabela 5. Teste Tukey para os resultados de compressão simples e relações água/aglomerante

\begin{tabular}{|c|c|c|c|c|c|c|}
\hline Experimento & $\mathrm{N}$ & Média (MPa) & CV (\%) & $p$-valor $F$ & $\begin{array}{l}\text { Grupos } \\
\text { Tukey }\end{array}$ & \\
\hline Puro 1:3 $(0,57)$ & 4 & 4,89 & 1,3 & \multirow[t]{6}{*}{0,0001} & & A \\
\hline Puro 1:3 $(0,69)$ & 4 & 4,30 & 2,7 & & & B \\
\hline Puro 1:3 $(0,46)$ & 4 & 3,89 & 1,1 & & & C \\
\hline CCA 1:3 $(0,57)$ & 4 & 3,47 & 2,4 & & & D \\
\hline CCA 1:3 $(0,69)$ & 4 & 2,81 & 4,0 & & & E \\
\hline CCA 1:3 $(0,46)$ & 4 & 2,65 & 1,9 & & & E \\
\hline Puro 1:4 $(0,57)$ & 4 & 3,76 & 4,4 & \multirow[t]{6}{*}{0,0001} & & A \\
\hline Puro 1:4 $(0,69)$ & 4 & 3,70 & 4,1 & & & A \\
\hline Puro $1: 4(0,46)$ & 4 & 3,24 & 4,1 & & & B \\
\hline CCA 1:4 $(0,57)$ & 4 & 2,99 & 2,3 & & C & B \\
\hline CCA 1:4 $(0,69)$ & 4 & 2,81 & 4,1 & & C & \\
\hline CCA 1:4 $(0,46)$ & 4 & 2,25 & 4,6 & & & D \\
\hline
\end{tabular}

Fonte: Autor (2017) 
Figura 7. Resultados de resistência à compressão simples aos 28 dias para relações àgua/aglomerante

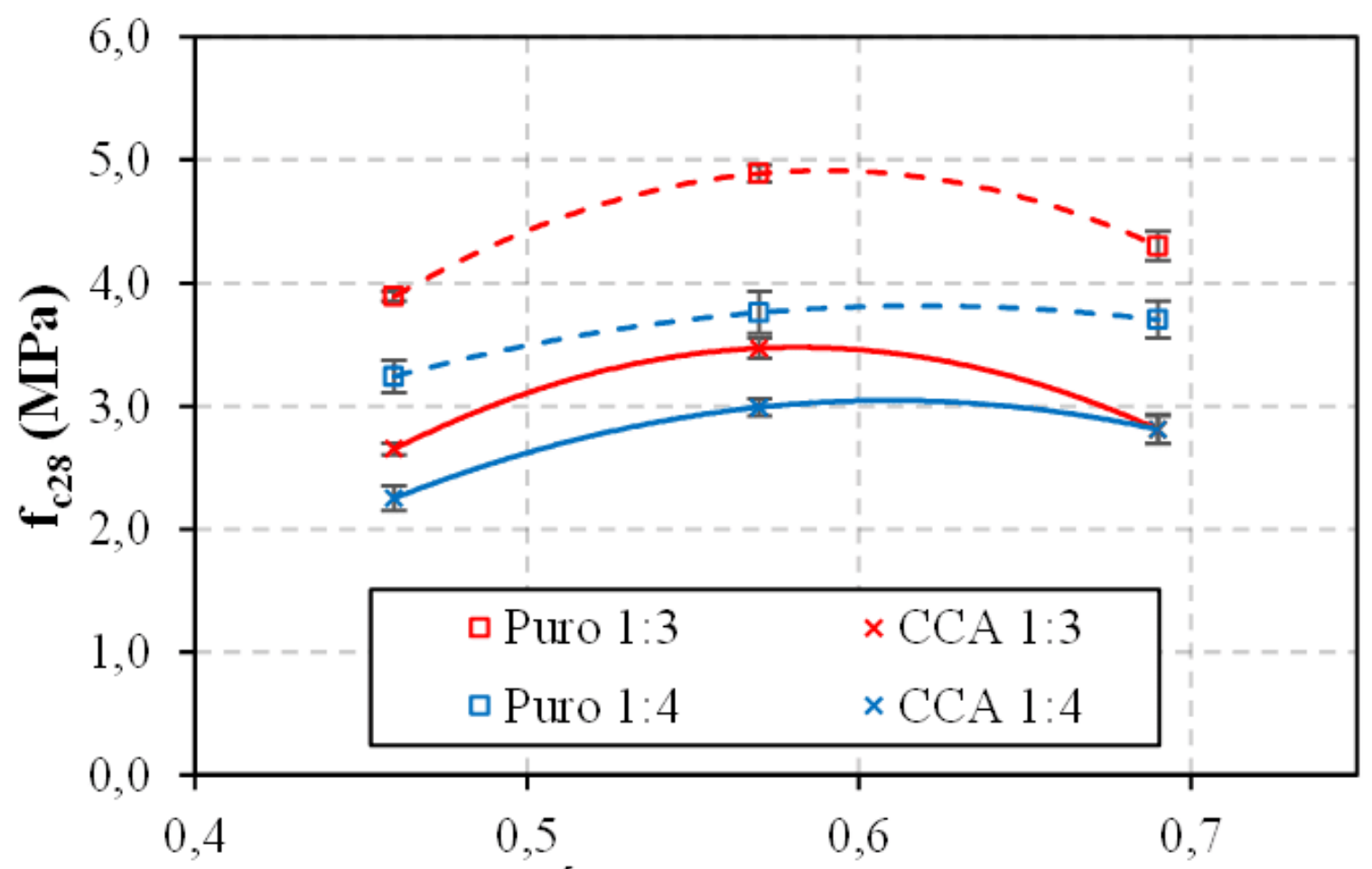

\section{Água/Aglomerante}

Quanto a comparação da resistência à compressão no tipo de mistura 1:3, a análise de variância ANOVA evidenciou que, pelo menos uma das composições, é diferente dos demais $(p<0,0001)$. O Teste de Tukey para comparações múltiplas mostrou cinco grupos de médias distintas, rotulados como A, B, C, D e E. Para esse caso, o grupo de experimentos PURO com relação água/aglomerante 0,57 foi o que mostrou melhor resistência. Para as composições com adição de CCA, a relação água/aglomerante de melhor resistência foi idêntica.

Nesse sentido, avaliando-se as misturas 1:4, também foram encontradas diferenças estatisticamente significativas entre os resultados $(p<0,0001)$ apontados pelo teste ANOVA. A sinalização pelas letras $A, B, C$ e $D$ delimitam quatro grupos de médias distintas. Para esse caso, os grupos de experimentos PURO, com relação 
água/aglomerante de 0,57 e 0,69, apresentaram as maiores resistências, não diferindo significativamente entre si. O experimento PURO com relação 0,46 não foi superior ao experimento CCA de relação 0,57 , que, por outro lado, não difere significativamente do CCA de relação 0,69 , formando um grupo de resistência semelhante $(C)$.

A adição de CCA provocou uma diminuição nos resultados de compressão simples, o que pode ser explicado pela redução de cimento na mistura. Ainda assim, todas as misturas avaliadas ultrapassaram o limite de 1,5 MPa de compressão simples aos 28 dias para blocos de concreto para alvenaria de vedação estabelecido na NBR 15961 (ABNT, 2011). Por fim, nota-se que a adição de $10 \%$ de CCA não influenciou significativamente nos resultados de relação água/aglomerante. Dessa forma, pelas linhas de tendência, os valores ótimos para relação água/aglomerante são de 0,58 e 0,63 para os traços $1: 3$ e 1:4, respectivamente.

De forma análoga ao comportamento das fibras de $\mathrm{CA}$, foi avaliado o compósito dos materiais na argamassa pela microscopia eletrônica MEV, após os ensaios de resistência à compressão. Dessa maneira, a Figura 8 (A) mostra o preenchimento completo de meia CA pela argamassa, mostrando boa homogeneização do compósito. A adesão por compatibilidade na interface entre os materiais pode ser observada junto à fratura na interface CA e argamassa Figura 8 (B), em que é possível perceber que a argamassa copiou as irregularidades da superfície externa da CA. Logo, as Figuras 8 ( $C$ e D) mostram boa afinidade entre os materiais utilizados na mistura.

RC: 87828

Disponível em: https://www.nucleodoconhecimento.com.br/engenharia-civil/cimento-portalnd 


\section{MULTIDISCIPLINARY SCIENTIFIC JOURNAL

Figura 8. Superfícies de fratura da argamassa, imagens do Microscópio Eletrônico de Varredura
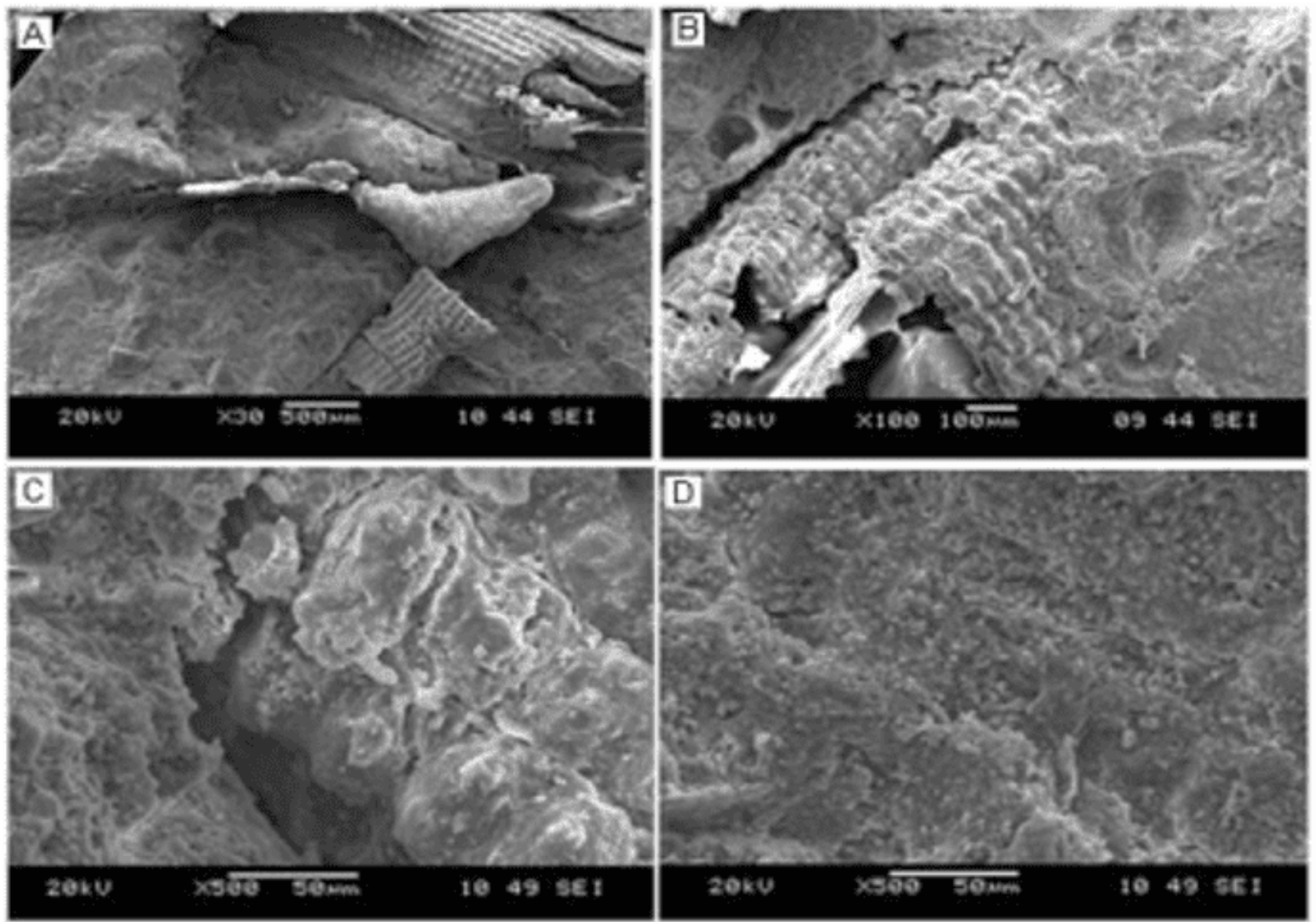

Fonte: Laboratório de Metalurgia Física - DEM/UFSM (2017)

A aderência por convergência propiciada na homogeneização com a matriz, mostra a afinidade entre os materiais, para o compósito casca de arroz e argamassa, que pode ser confirmada analisando-se as imagens obtidas da superfície de fraturas. A boa assimilação da mistura, fator esse que permite que se tenha uma próxima relação de densidade para o compósito, faz constatar o bom desempenho relacionado às características físicas e mecânicas.

\section{CONCLUSÃO}

As caracterizações dos materiais demonstraram a possibilidade de uso da CA como substituinte parcial ao agregado miúdo, desde que processadas anteriormente por RC: 87828

Disponível em: https://www.nucleodoconhecimento.com.br/engenharia-civil/cimento-portalnd 
banhos térmicos, os quais visam melhorar a compatibilidade dessa com os compósitos da argamassa. A CCA foi delineada como substituinte parcial do cimento, ainda que apresentasse atividade pozolânica com cal insuficiente para uso em argamassas. Porém, foi avaliada positivamente para composição no fechamento dos poros da argamassa

A CCA apresentou área específica e distribuição de partículas satisfatória para seu uso como aglomerante, bem como as características apresentadas pela CA também se mostraram satisfatórias para seu uso como agregado leve. À medida que se adicionava CCA, ocorria diminuição gradual da resistência em corpos de prova. Para cada adição de 5\% de CCA, tem-se uma diminuição média de $6 \%$ na resistência dos corpos de prova.

Em síntese, quatro traços de argamassa (1:3 e 1:4, com e sem adição de cinza) foram avaliados quanto a relação água/aglomerante e resistência à compressão simples. A aplicação dessa encontra-se no limite para maior de 1,5 MPa para blocos de concreto e/ou cerâmico NBR 15961 (ABNT, 2011) em alvenaria de vedação, fator que foi atingido por todas amostras estudadas, o que viabilizou o uso dos subprodutos em argamassas para blocos de vedação. A adição de cinza não apresentou variação nas relações água/aglomerante, ainda que tenha diminuído a resistência à compressão de forma geral. A pesquisa ainda apresentou que a inclusão de CCA pode trazer resultados semelhantes aos puros (sem adição) em alguns casos. Outrossim, pela microscopia eletrônica de varredura do compósito da argamassa após a fratura por compressão simples, foi observada uma adesão por compatibilidade na interface, uma homogeneização com a matriz e afinidade entre os materiais.

Por fim, pode-se considerar que o uso de materiais alternativos, como cinza e CA em argamassas de cimento, pode ser executado, desde que haja um estudo de dosagem adequado, englobando a relação água/aglomerante e resistências a compressão compatíveis com normativas. 


\section{REFERÊNCIAS}

ASSOCIAÇÃO BRASILEIRA DE NORMAS TÉCNICAS. NBR 10004: Resíduos Sólidos - Classificação. Rio de Janeiro, 2004.

ASSOCIAÇÃO BRASILEIRA DE NORMAS TÉCNICAS. NBR 12826: Cimento Portland e outros materiais em pó - Determinação do índice de finura por meio de peneirador aerodinâmico. Rio de Janeiro, 2014.

ASSOCIAÇÃO BRASILEIRA DE NORMAS TÉCNICAS. NBR 15961: Alvenaria estrutural - Blocos de concreto. Rio de Janeiro, 2011.

ASSOCIAÇÃO BRASILEIRA DE NORMAS TÉCNICAS. NBR 5751: Materiais pozolânico - Determinação da atividade pozolânica com cal aos sete dias. Rio de Janeiro, 2015.

ASSOCIAÇÃO BRASILEIRA DE NORMAS TÉCNICAS. NBR 16372: Cimento Portland e outros materiais em pó - determinação de finura pelo método de permeabilidade ao ar (método de Blaine). Rio de Janeiro, 2015.

ASSOCIAÇÃO BRASILEIRA DE NORMAS TÉCNICAS. NBR 16605: Cimento Portland e outros materiais em pó - Determinação da massa específica. Rio de Janeiro, 2017.

ASSOCIAÇÃO BRASILEIRA DE NORMAS TÉCNICAS. NBR 16697: Cimento Portland - Requisitos. Rio de Janeiro, 2018.

ASSOCIAÇÃO BRASILEIRA DE NORMAS TÉCNICAS. NBR NM 22: Cimento Portland com adições de materiais pozolânicos - Análise química - Método de arbitragem. Rio de Janeiro, 2012.

RC: 87828

Disponível em: https://www.nucleodoconhecimento.com.br/engenharia-civil/cimento-portalnd 
ASSOCIAÇÃO BRASILEIRA DE NORMAS TÉCNICAS. NBR NM 22: Cimento Portland com adições de materiais pozolânicos - Análise química - Método de arbitragem. Rio de Janeiro, 2012.

ASSOCIAÇÃO BRASILEIRA DE NORMAS TÉCNICAS. NBR NM 45: Agregados Determinação da massa unitária e do volume de vazios. Rio de Janeiro, 2006.

BEZERRA, I. M. T. Cinza da casca de arroz utilizada em argamassas de assentamento e revestimento. Dissertação (Mestrado em Engenharia Civil) Universidade Federal de Campina Grande. Campina Grande/PB, 2010. 108 p.

BUI, D. D.; HU, J.; STROEVEN, P. Particle size effect on the strength of rice husk ash blended gap-graded Portland cement concrete. Cement \& Concrete Composites, v. 27, n. 3, p. 357-366, 2005.

CARVALHO, A. C. de. Estudo comparativo entre placas de argamassa armada com casca de arroz e tijolo cerâmico de oito furos para melhoria do desempenho térmico nas habitações de clima tropical continental. Dissertação (Mestrado em Engenharia Civil) - Universidade Federal do Mato Grosso, Cuiabá/MT, 2004. 98 p.

COMPANHIA NACIONAL DE ABASTECIMENTO (CONAB). Acompanhamento da safra brasileira grãos. V. 7 - Safra 2019/20 - N. 8 - Oitavo levantamento, Brasília, Maio, 2020.

DAL MOLIN, D. C. C.; VIEIRA, G. L.; LIMA, F. B. Resistência e durabilidade de concretos produzidos com agregados reciclados provenientes de resíduos de construção e demolição. Engenharia Civil UM (Braga), Minho - Portugal, n.19, p. 518, 2004.

FERREIRA, R. DE C.; GOBO, J. C. DA C.; CUNHA, A. N. H. Incorporação da casca de arroz e da braquiária e seus efeitos nas propriedades físicas e mecânicas de tijolos de solo-cimento. Revista Eng. Agrícola. Jaboticabal/SP, v. 28, n.1. p. 1-11, 2008. 
FERREIRA, R. B. Influência das adições minerais nas características do concreto de cobrimento e seu efeito na corrosão de armaduras induzidas por cloretos. Dissertação (Mestrado em Engenharia Civil) - Universidade Federal de Goiás. Goiânia/GO, 2003. 255 p.

HANAFI, S.; ABO-EL-ENEIN, S. A.; IBRAHIM, D. M.; EL-HEMALY, S. A. Surface Properties of Silicas Produced by Thermal Treatment of Rice- Husk Ash. Thermochimica Acta, v. 37, n. 2. p. 137- 143, 1980. https:/doi.org/10.1016/0040$6031(80) 80034-71980$

HARIMA, E.; SOUZA, M. F. Estabilização da fase beta e obtenção da fase alfa da cristobalita a partir do resíduo da casca de arroz. Anais: Congresso Brasileiro de Engenharia e Ciência dos Materiais, ed. 12, São Paulo/SP, 1996.

ISAIA, G. C. Dosagem de concreto com casca de arroz para produtos pré-moldados. Colloquia, Porto Alegre - RS, junho. p. 205-218, 1987.

ISAIA, G. C. Efeito de misturas binárias e ternárias de pozolanas em concreto de elevado desempenho: um estudo de durabilidade com vistas à corrosão da armadura. Tese (Doutorado em Engenharia Civil) - Escola Politécnica da Universidade de São Paulo, São Paulo/SP, 1995.

JOHN, V. M. Reciclagem de resíduos na construção civil. Tese (Doutorado em Engenharia Civil) - Escola Politécnica, Universidade de São Paulo, São Paulo/SP, 2000.

LABORATÓRIO DA ASSOCIAÇÃO BRASILEIRA DE CIMENTO PORTLAND (ABCP/SP). Relatório da análise química da cal. São Paulo/SP, 2017.

LABORATÓRIO DA ASSOCIAÇÃO BRASILEIRA DE CIMENTO PORTLAND (ABCP/SP). Relatório da análise química da casca de arroz. São Paulo/SP, 2017. 
LABORATÓRIO DA ASSOCIAÇÃO BRASILEIRA DE CIMENTO PORTLAND (ABCP/SP). Relatório da caracterização física da cinza de casca de arroz. São Paulo/SP, 2017.

LABORATÓRIO DA ASSOCIAÇÃO BRASILEIRA DE CIMENTO PORTLAND (ABCP/SP). Relatório da determinação da atividade pozolânica com cal da cinza de casca de arroz. São Paulo/SP, 2017.

LABORATÓRIO DA ASSOCIAÇÃO BRASILEIRA DE CIMENTO PORTLAND (ABCP/SP). Relatório de análise química dos cimentos C1 e C2. São Paulo/SP, 2017.

LABORATÓRIO DA CENTRAL ANALÍTICA (CADEQ) - Departamento de Engenharia Química da Universidade Federal de Santa Maria. Relatório da análise química da areia. Santa Maria/RS, 2017.

LABORATÓRIO DA CENTRAL ANALÍTICA (CADEQ) - Departamento de Engenharia Química da Universidade Federal de Santa Maria. Relatório da determinação da composição morfológica por difração de Raios-X da casca de arroz. Santa Maria/RS, 2017.

LABORATÓRIO DE DESENVOLVIMENTO E CARACTERIZAÇÃO DE MATERIAIS (LDCM). Relatório de determinação da composição morfológica por Difração de Raios-X da casca de arroz. Criciúma/SC, 2017.

LABORATÓRIO DE METALURGIA FÍSICA - Departamento de Engenharia Mecânica da Universidade Federal de Santa Maria. Relatório de empacotamento no Microscópio Eletrônico de Varredura (MEV) para análise da superfície da casca de Arroz. Santa Maria/RS, 2017.

LIMA, M. S. Utilização do resíduo de caulim para uso em blocos de concreto sem função estrutural. Dissertação (Mestrado em Engenharia Civil) - Universidade Federal de Campina Grande, Campina Grande/PB, 2005.

$\mathrm{RC}: 87828$

Disponível em: https://www.nucleodoconhecimento.com.br/engenharia-civil/cimento-portalnd 
MARINELLI, A. L., MONTEIRO, M. R., AMBROSIO, J. D. RANCIFORTI, M. C., KOBAYACHI, M., NOBRE, A. D. Desenvolvimento de compósitos poliméricos com fibras vegetais naturais da biodiversidade: uma contribuição para a sustentabilidade amazônica. Polímeros, Jun 2008, vol.18, no.2, p.92-99, 2008. http://dx.doi.org/10.1590/S0104-14282008000200005

MARTINEZ, R. G.; FERREIRA, H. C.; NOGUEIRA, M. C. J. A.; NOGUEIRA, J. S. Placa de argamassa composta com casca de arroz para painéis de fechamento vertical em habitações populares. Anais: Seminário Mato-Grossense de Habitação de Interesse Social, ed. 1. Cuiabá: CEFETMT-UFMT. p. 509-524, 2005.

MEHTA, P. K. Rice Husk Ash: A Unique Supplementary Cementing Material. Advances in Concrete Technology, Ottawa: Canmet. 407-431 p., 1992.

MILANI, A. P. S. Avaliação Física, Mecânica e Térmica do Material Solo-Cimento Cinza de Casca de Arroz e seu Desempenho como Parede Monolítica. Tese (Doutorado em Engenharia Civil) - Universidade Estadual de Campinas, Faculdade de Engenharia Agrícola, Campinas/SP, 2008.

NAIR, D. G.; FRAAIJ, A.; KLAASSEN, A. K.; KENTGENS, A. P. M. A structural investigation relating to the pozzolanic activity of rice husk ashes. Cement and Concrete Research, Elmsford, v. 38, n. 1. p. 861-869, 2008.

POUEY, M. T. F. Beneficiamento da cinza de casca de arroz residual com vistas à produção de cimento composto e/ou pozolânico. Tese (Doutorado em Engenharia Civil) - Universidade Federal do Rio Grande do Sul, Escola de Engenharia, Porto Alegre/RS, 2006.

RIPOLI FILHO, F. Estudo Experimental de um Compósito de Argamassa Utilizando Cinza e Casca de Arroz, Aplicado em Blocos de Vedação. 2019. 210 f. Tese (Doutorado em Engenharia Civil) - Universidade Federal de Santa Maria, Santa Maria, Rio Grande do Sul, 2019. 
SILVA, E. J. Contribuição para utilização de cinza de casca de arroz na construção civil. Dissertação (Mestrado em Engenharia Civil) - Faculdade de Engenharia - UNESP, Ilha Solteira/SP, 2009.

SOUZA, J. DE. Estudo da durabilidade de argamassas utilizando cinzas e casca de arroz. Tese (Doutorado em Engenharia Civil) - Universidade Federal de Campina Grande, Campina Grande/PB, 2008.

TASHIMA, M. M.; SILVA, C. A. R. L.; AKASAKI, J. L. Concreto com adição de cinza de casca de arroz (CCA) obtida através de um processo de combustão não controlada. Anais: Jornada Sud-Americanas de Ingenieria Estructural, ed 31. Mendonza, Argentina, 2004.

TIBONI, R. A. Utilização da cinza da casca de arroz de termoelétrica como componente do aglomerante de compósitos à base de cimento Portland. Dissertação (Mestrado em Engenharia Civil) - Universidade de São Paulo, São Carlos/SP, 2007.

Enviado: Março, 2021

Aprovado: Junho, 2021. 